\title{
Germinação e vigor de sementes peletizadas de tomate
}

\author{
Ademar P. de Oliveira ${ }^{1,3}$, Riselane de L. A. Bruno ${ }^{1} \&$ Edna U. Alves ${ }^{2}$ \\ 1 CCA/UFPB. CP 02, CEP 58.397-000, Areia, PB. Fone: (83) 362-2300. E-mail: ademar@cca.ufpb.br (Foto) \\ 2 Doutoranda, UNESP/FCAV. CEP 14884-900, Jaboticabal, SP \\ ${ }^{3}$ Bolsista do $\mathrm{CNPq}$
}

Protocolo $111-23 / 7 / 2001$

\begin{abstract}
Resumo: Definir o tipo de substrato, a temperatura e a forma de hidratação mais adequados para avaliar a germinação e o vigor de sementes peletizadas de tomate foi o objetivo principal deste trabalho, razão pela qual se realizou o experimento em laboratório, utilizando-se delineamento inteiramente casualizado, com os tratamentos distribuídos em esquema fatorial $3 \times 4 \times 2$, com os fatores temperaturas $\left(25,30^{\circ} \mathrm{C}\right.$ constantes e $20-30{ }^{\circ} \mathrm{C}$ alternada), substratos (entre papel, sobre papel, entre areia e entre vermiculita) e formas de hidratação (água destilada ou nitrato de potássio) em quatro repetições. Analisaram-se os seguintes parâmetros: porcentagem de germinação, primeira contagem e velocidade de germinação e massa seca de plântulas. Os substratos entre areia e vermiculita umedecidos com água em temperatura constante de 25 ou $30{ }^{\circ} \mathrm{C}$, foram mais eficientes na avaliação da germinação e do vigor em sementes peletizadas de tomate. A temperatura alternada de $20-30{ }^{\circ} \mathrm{C}$ e os substratos entre e sobre papel, não se mostraram adequados para avaliar sementes peletizadas de tomate.
\end{abstract}

Palavras-chave: Lycopersicon esculentum, substratos, temperaturas, qualidade de sementes

\section{Germination and vigor of pelleted seeds of tomato}

\begin{abstract}
This study was conducted with the objective of determination of most adequate substrate, temperature and forms of hydration applied in germination and vigor tests of pelleted seeds of tomato. The experiment was carried out at the Seed Analysis Laboratory of the Department of Agronomy of the Federal University of Paraíba, Brazil. The experimental design adopted was a completely randomized and the treatments were distributed in a $3 \times 4 \times 2$ factorial scheme, the factors studied were temperature $\left(25,30^{\circ} \mathrm{C}\right.$ constant and $20-30{ }^{\circ} \mathrm{C}$ alternate), substrates (on and between paper sheets sand and vermiculite) and the hydration for which distilled water and potassium nitrate were used. The effects were evaluated considering percentage of germination, first counting, germination speed and weight of dry matter of seedlings. The substrates sand and vermiculite moistened with distilled water at constant temperatures of 25 or $30^{\circ} \mathrm{C}$ were the most efficient for germination and vigor test of pelleted seeds of tomatoes. The alternated temperatures $20-30{ }^{\circ} \mathrm{C}$ and substrates on paper and between paper sheets were not found to be adequate for evaluation of pelleted seeds of tomato.
\end{abstract}

Key words: Lycopersicon esculentum, substrates, temperatures, seeds quality

\section{INTRODUÇÃO}

A peletização de sementes tem como objetivo principal melhorar seu comportamento, tanto do ponto de vista fisiológico como do econômico (Silveira, 1997; Silva \& Nakagawa, 1998a). O arranjo das partículas finas e a ocupação dos espaços entre elas (poros) pelo cimentante e pela água de irrigação, formam uma barreira à troca gasosa entre a semente e o ambiente externo ao pélete provocando, geralmente, atraso no processo de germinação, o que constitui o principal entrave à ampla utilização de sementes peletizadas (Silva \& Nakagawa, 1998b). A germinação pode ser retardada de um a dois dias (Roos \& Moore, 1975) até 20 dias ou mais (Sachs et al., 1981) mas, geralmente, a porcentagem de germinação é semelhante à de sementes nuas.

Demonstrando a relação entre a granulometria do material utilizado na peletização e a velocidade de germinação das sementes, Sachs et al. (1982) compararam o desempenho de sementes de pimentão doce nuas com péletes-semente confeccionados com argila e outros com uma primeira camada de areia fina e recobertos com areia grossa. Os autores observaram que as sementes peletizadas com areia apresentaram maior velocidade de germinação que as peletizadas com argila; 
no entanto, não atingiram a mesma velocidade de germinação das sementes nuas, embora as porcentagens finais de germinação tenham sido semelhantes. Resultados idênticos foram observados por Santos et al. (2000) em sementes de alface, Martins et al. (2001) em sementes de brócolos e Resende et al. (2001) em sementes de pimentão. No entanto, Davide et al. (2001) em sementes de eucalipto e Almeida et al. (2001) em sementes de mutamba, verificaram efeitos diferentes.

Comparando a qualidade de sementes nuas e recobertas de brócolos, Giomo et al. (2001) verificaram que os materiais de recobrimento utilizados não afetaram o vigor das mesmas. No entanto, em sementes de pimentão (Resende et al., 2001) e de tomate (Pereira et al., 2001) houve redução significativa no vigor, em função do recobrimento, com conseqüentes prejuízos à germinação.

Os substratos utilizados nos testes de germinação também apresentam grande influência, porque fatores como estrutura, aeração, capacidade de retenção de água e grau de infestação de patógenos, podem variar de acordo com o tipo de material utilizado. Conforme as Regras para Análise de Sementes (Brasil, 1992) na escolha do substrato se deve levar em consideração o tamanho da semente, sua exigência em relação à quantidade de água, sua sensibilidade ou não à luz e a facilidade que este oferece para a realização das contagens e avaliação das plântulas. As espécies apresentam comportamento diferenciado em relação à sua sensibilidade a uma disponibilidade maior ou menor de água no substrato de germinação devido, possivelmente, ao tipo de material de cobertura empregado no recobrimento.

Alguns substratos têm sido testados, como carvão, esfagno, vermiculita, pano, papel-toalha, papel-filtro, papel mata-borrão, terra e areia. A vermiculita e a areia têm sido consideradas de excelente qualidade para germinação de sementes, principalmente pela baixa contaminação de microrganismos (Figliolia et al., 1993).

Além da umidade e do tipo de substrato utilizado, outros fatores podem exercer influência nos resultados dos testes de germinação das sementes. Em seus experimentos, Macchia et al. (1983) relataram que a temperatura ótima para germinação de sementes de alface e cebola foi mais baixa para sementes recobertas que para as nuas; no entanto, similar para endívia e tomate, em que a diferença entre a temperatura máxima e mínima de germinação, foi mais estreita.

O teste de germinação utilizado em laboratório para avaliar a qualidade da semente é realizado sob condições de temperatura e substratos ideais para cada espécie. As Regras para Análise de Sementes (Brasil, 1992) recomendam, para testes de germinação em sementes nuas de tomate, os substratos sobre papel, entre papel e entre areia, temperatura alternada de $20-30{ }^{\circ} \mathrm{C}$ e hidratação com água ou nitrato de potássio. A temperatura influencia a absorção de água pela semente, as reações bioquímicas que regulam o metabolismo necessário para iniciar o processo germinativo (Carvalho \& Nakagawa, 2000), a velocidade e a porcentagem final de germinação (Bewley \& Black, 1985).

As sementes são capazes de germinar sob uma amplitude de temperatura definida para cada espécie (Bewley \& Black, 1985) existindo uma temperatura ótima, mínima e máxima para a germinação, sendo ótima aquela em que a mais alta porcentagem de germinação é obtida no menor espaço de tempo mínima e máxima, respectivamente, como a mais baixa e mais alta temperatura, na qual a germinação não ocorre (Mayer \& PoljakoffMayber, 1989). A temperatura ótima para a maioria das espécies está entre 20 a $30{ }^{\circ} \mathrm{C}$ e a máxima entre 35 e $40{ }^{\circ} \mathrm{C}$ (Marcos Filho, 1986).

O objetivo do presente trabalho foi estudar a influência de substratos, temperaturas e formas de hidratação na germinação e no vigor de sementes peletizadas de tomate.

\section{MATERIAL E MÉTODOS}

O trabalho foi realizado no Laboratório de Análise de Sementes do Centro de Ciências Agrárias da Universidade Federal da Paraíba, em maio de 2001, com sementes peletizadas de tomate híbrido Hypeel 108, procedentes de um lote comercial da "Royal Sluis - Sementes".

Utilizaram-se as temperaturas constantes de 25 e $30{ }^{\circ} \mathrm{C}$ e alternadas $20-30{ }^{\circ} \mathrm{C}$, nos substratos sobre papel e entre papel "germitest", entre areia e entre vermiculita, previamente esterilizados. Cada tratamento constou de 50 sementes por repetição, que foram colocadas em germinador sob fotoperíodo de $8 \mathrm{~h}$. O substrato papel foi umedecido com uma quantidade equivalente a 2,5 vezes o seu peso seco, enquanto os substratos areia e vermiculita, com $80 \mathrm{~mL}$ dos hidratantes.

Para se avaliar os efeitos dos tratamentos sobre a germinação, realizaram-se contagens nos quarto e sétimo dias após a instalação do ensaio; simultaneamente, avaliou-se o vigor das sementes pelos testes de primeira contagem, índice de velocidade de germinação (IVG) e peso de massa seca de plântulas.

O IVG foi determinado registrando-se diariamente o número de sementes germinadas a partir do quarto até o sétimo dia e calculado pela fórmula proposta por Maguire (1962):

$$
\mathrm{IVG}=\mathrm{G}_{1} / \mathrm{N}_{1}+\mathrm{G}_{2} / \mathrm{N}_{2}+\ldots+\mathrm{G}_{\mathrm{n}} / \mathrm{N}_{\mathrm{n}}
$$

em que:

IVG - Índice de velocidade de germinação, $\mathrm{d}^{-1}$

$\mathrm{G}_{1}, \mathrm{G}_{2} \mathrm{e}_{\mathrm{n}}$ - número de plântulas normais computadas nas primeira, segunda e última contagem

$\mathrm{N}_{1}, \mathrm{~N}_{2}$ e $\mathrm{N}_{\mathrm{n}}$ - número de dias após a implantação do teste

Para determinação da massa seca, transferiram-se as plântulas normais, obtidas na última contagem, para a estufa regulada a $65^{\circ} \mathrm{C}$, por $24 \mathrm{~h}$. Após pesagem em balança analítica com precisão de $0,001 \mathrm{~g}$, dividiu-se a massa seca total pelo número de plântulas, para obtenção da massa seca por plântula.

Os tratamentos foram arranjados em delineamento experimental inteiramente casualizado, em esquema fatorial $3 \times 4 \times 2$, com os fatores temperaturas: 25 e $30{ }^{\circ} \mathrm{C}$ constantes e $20-30{ }^{\circ} \mathrm{C}$ alternadas, substratos: sobre papel e entre papel "germitest", entre areia e vermiculita, e formas de hidratação: água destilada e solução de nitrato de potássio a $0,2 \%$ em quatro repetições de 50 sementes. Empregou-se o teste de Tukey, ao nível de 5\% de probabilidade, para comparação entre as médias, quando houve significância no teste $\mathrm{F}$. 


\section{RESULTADOS E DISCUSSÃO}

No estudo da interação substrato $\mathrm{x}$ hidratação, os maiores percentuais de germinação foram obtidos com os substratos entre areia e vermiculita umedecidos com água e entre areia umedecida com nitrato de potássio. Com relação à interação temperatura $\mathrm{x}$ hidratação, observou-se que na temperatura alternada de $20-30{ }^{\circ} \mathrm{C}$ na presença de água, ocorreu a menor porcentagem de germinação, enquanto na presença do nitrato de potássio não houve diferença estatística entre as temperaturas utilizadas (Tabela 1).

De modo geral, as Regras para Análise de Sementes (Brasil, 1992) recomendam, para avaliação de sementes peletizadas, os substratos papel, areia e, em certos casos, o solo. No entanto, os resultados obtidos neste trabalho permitem inferir-se que, para se avaliar as sementes peletizadas de tomate, deve-se empregar as temperaturas constantes de 25 ou $30^{\circ} \mathrm{C}$ e os substratos entre areia e vermiculita, umedecidos de acordo com suas prescrições. Seguindo recomendações das Regras para Análise de Sementes, para avaliar sementes peletizadas de brócolos (Martins et al., 2001), pimentão (Resende et al., 2001), eucalipto (Davide et al., 2001) e mutamba (Almeida et al., 2001), nas temperaturas de 25 e/ou $30{ }^{\circ} \mathrm{C}$ não constataram diferenças significativas na porcentagem de germinação dessas espécies.

O bom desempenho das sementes nos substratos entre areia e vermiculita deveu-se, provavelmente, à manutenção de umidade no substrato, proporcionando condições mais favoráveis ao crescimento das plântulas. Como ocorreu um crescimento elevado das plântulas, o fato exigiu a retirada das tampas dos gerbox, o que promoveu ressecamento nos substratos entre e sobre papel. Peterson \& Cooper (1979) relatam que a variação na disponibilidade de água dos substratos causa, freqüentemente, prejuízos à germinação das sementes, enquanto Andrade \& Pereira (1994) em estudos realizados com o substrato rolo de papel-toalha, sobre papel de filtro e sobre vermiculita, demonstraram que todos influenciaram sensivelmente a germinação, devido à capacidade de retenção de água, aliada às características intrínsecas que regulam o fluxo de água para as sementes, sendo que o rolo de papel foi o que mostrou menor capacidade de retenção de água, apesar dos rolos estarem dentro de sacos plásticos perfurados.

A eficiência das temperaturas de 25 e $30^{\circ} \mathrm{C}$ na germinação está, provavelmente, relacionada ao fato de que a temperatura adequada para a germinação das espécies tropicais e subtropicais, segundo Marcos Filho (1986) e Borges \& Rena (1993) varia de 20 a $30{ }^{\circ} \mathrm{C}$, e de acordo com Albrecht et al. (1986) esta temperatura se encontra entre 26,5 e $35^{\circ} \mathrm{C}$.

Nos resultados de vigor no teste de primeira contagem e na massa seca de plântulas, a exemplo do teste de germinação, também ocorreu interação significativa entre substrato, temperatura e hidratação. Analisando-se a interação substrato $x$ hidratação, verificou-se que os substratos entre areia umedecida com água e vermiculita umedecida com nitrato de potássio, propiciaram o maior vigor (maior número de sementes na primeira contagem). Com relação à interação temperatura $x$ hidratação, plântulas mais vigorosas ocorreram na primeira contagem de germinação, nas temperaturas de 25 e $30{ }^{\circ} \mathrm{C}$, quando os substratos foram umedecidos com água (Tabela 1 ).

Para as médias de massa seca de plântulas, pelos resultados da interação substrato x hidratação constatou-se que nos substratos entre areia e vermiculita umedecidos com água e areia umedecida com nitrato de potássio, as plântulas apresentaram-se mais vigorosas, enquanto na interação temperatura $\mathrm{x}$ hidratação, o maior vigor (conteúdo de massa seca nas plântulas) ocorreu quando se empregou a temperatura de $25{ }^{\circ} \mathrm{C}$, independentemente da forma de hidratação (Tabela 1). Esses resultados demonstram, mais uma vez, a importância do emprego de areia e vermiculita na avaliação de sementes peletizadas de tomate.

O fato das sementes apresentarem melhor desempenho nos substratos areia e vermiculita, provavelmente esteja relacionado com a manutenção de água dos substratos, o que permitiu melhor desenvolvimento das plântulas. Apesar de não estar descrita nas Regras para Análise de Sementes (Brasil, 1992), Figliolia et al. (1993) relatam que a vermiculita vem sendo

Tabela 1. Germinação e primeira contagem de germinação de sementes e massa seca de plântulas de tomate ${ }^{1}$, em função das temperaturas, substratos e hidratação

\begin{tabular}{|c|c|c|c|c|c|c|}
\hline \multirow{3}{*}{ Substrato } & \multicolumn{2}{|c|}{ Germinação (\%) } & \multicolumn{2}{|c|}{ Primeira Contagem (\%) } & \multicolumn{2}{|c|}{ Massa Seca (g plântula ${ }^{-1}$ ) } \\
\hline & \multicolumn{6}{|c|}{ Hidratação } \\
\hline & Nitrato & Água & Nitrato & Água & Nitrato & Água \\
\hline Sobre papel & $75,00 \mathrm{cA}$ & $76,00 \mathrm{dA}$ & $67,00 \mathrm{cA}$ & $70,00 \mathrm{bA}$ & $0,0016 \mathrm{bB}$ & $0,0018 \mathrm{cA}$ \\
\hline Entre papel & $86,00 \mathrm{bA}$ & $84,00 \mathrm{cB}$ & $78,00 \mathrm{bA}$ & $45,00 \mathrm{cB}$ & $0,0016 \mathrm{bB}$ & $0,0017 \mathrm{cA}$ \\
\hline Areia & $90,00 \mathrm{aA}$ & $91,00 \mathrm{aA}$ & $86,00 \mathrm{aA}$ & $76,00 \mathrm{aB}$ & $0,0033 \mathrm{aB}$ & $0,0038 \mathrm{aA}$ \\
\hline Vermiculita & $89,00 \mathrm{aA}$ & $88,00 \mathrm{bA}$ & $78,00 \mathrm{bA}$ & $79,00 \mathrm{aA}$ & $0,0033 \mathrm{aA}$ & $0,0024 \mathrm{bB}$ \\
\hline $30^{\circ} \mathrm{C}$ & $87,00 \mathrm{aA}$ & $85,00 \mathrm{aB}$ & $81,00 \mathrm{aA}$ & $77,00 \mathrm{aB}$ & $0,0024 \mathrm{bB}$ & $0,0026 \mathrm{bA}$ \\
\hline $20-30{ }^{\circ} \mathrm{C}$ & $81,00 \mathrm{bB}$ & $85,00 \mathrm{aA}$ & $71,00 \mathrm{bA}$ & $55,00 \mathrm{cB}$ & $0,0021 \mathrm{cA}$ & $0,0021 \mathrm{cA}$ \\
\hline \multicolumn{7}{|l|}{$\mathrm{F}(5 \%)$} \\
\hline Substrato (S) & \multicolumn{2}{|c|}{$15,68 * *$} & \multicolumn{2}{|c|}{$83,12 * *$} & \multicolumn{2}{|c|}{$619,31 * *$} \\
\hline Temperatura $(\mathrm{T})$ & \multicolumn{2}{|c|}{$199,46^{* *}$} & \multicolumn{2}{|c|}{$93,27 * *$} & \multicolumn{2}{|c|}{$136,99 * *$} \\
\hline Hidratação (H) & \multicolumn{2}{|c|}{$0,21^{\mathrm{NS}}$} & \multicolumn{2}{|c|}{$96,91 * *$} & \multicolumn{2}{|c|}{$5,61 *$} \\
\hline
\end{tabular}

${ }^{1}$ Médias seguidas pela mesma letra, minúscula na coluna e maiúscula na linha, sob mesmo tratamento, não diferem, pelo teste de Tukey, a 0,01 de probabilidade.

** Significativo a $0,01, *$ Significativo a 0,05 , Ns Não significativo 
recomendada como excelente substrato para sementes de grandes dimensões e de formato arredondado, por permitir o desenvolvimento mais adequado de plântulas durante o teste de germinação, em função do maior contato entre as sementes e o substrato; no entanto, os autores comentam que o papel é o substrato mais utilizado.

Com relação a temperatura, a de $25{ }^{\circ} \mathrm{C}$ permitiu que as sementes expressassem seu máximo potencial fisiológico. Esta temperatura se situa dentro da faixa de temperaturas ótimas (20 a $30^{\circ} \mathrm{C}$ e 26,5 a $\left.35^{\circ} \mathrm{C}\right)$ e bem abaixo da faixa da temperatura máxima $\left(35\right.$ e $\left.40^{\circ} \mathrm{C}\right)$ para se avaliar sementes da maioria das espécies (Marcos-Filho, 1986; Albrecht et al., 1986; Borges \& Rena, 1993).

Em qualquer programa de controle de qualidade de sementes, é de fundamental importância a inclusão de testes de vigor, porque as recentes alterações no mercado produtor de sementes no Brasil têm exigido um controle eficiente e rigoroso, em que os testes de vigor são obrigatoriamente incluídos (Vieira et al., 2001). Também sua avaliação tem sido rotina nas indústrias sementeiras e tem evoluído à medida que os testes disponíveis vêm sendo aperfeiçoados, para permitir a obtenção de resultados consistentes e reproduzíveis, além da exigência de rapidez, simplicidade e viabilidade econômica (Martins et al., 2001); portanto, os resultados obtidos neste trabalho poderão contribuir para a avaliação da qualidade de sementes peletizadas de tomate.

Os substratos, as temperaturas e as formas de hidratação, agiram de forma independente sobre o índice de velocidade de germinação. Os substratos entre areia e vermiculita, as temperaturas de 25 e $30^{\circ} \mathrm{C}$ e o umedecimento dos substratos com água, proporcionaram os mais elevados índices de velocidade de germinação (Tabela 2). De acordo com Carvalho \& Nakagawa (2000) a temperatura ótima para se avaliar porcentagem de germinação em sementes nuas, é diferente da ótima para velocidade de germinação mas, para sementes peletizadas de tomate, os maiores valores para germinação e

Tabela 2. Índice de velocidade de germinação de plântulas de tomate $^{1}$, em função das temperaturas, substratos e formas de hidratação

\begin{tabular}{lc}
\hline Substratos & IVG \\
\hline Sobre papel & $10,15 \mathrm{~b}$ \\
Entre papel & $10,56 \mathrm{~b}$ \\
Areia & $11,39 \mathrm{a}$ \\
Vermiculita & $11,26 \mathrm{a}$ \\
\hline Temperaturas & \\
$25^{\circ} \mathrm{C}$ & $11,07 \mathrm{a}$ \\
$30^{\circ} \mathrm{C}$ & $11,01 \mathrm{a}$ \\
$20-30^{\circ} \mathrm{C}$ & $10,43 \mathrm{~b}$ \\
\hline Hidratação & \\
Água destilada & $11,07 \mathrm{a}$ \\
Nitrato & $10,60 \mathrm{~b}$ \\
\hline $\mathrm{F}(5 \%)$ & \\
Substrato $(\mathrm{S})$ & $13,85^{* *}$ \\
Temperatura $(\mathrm{T})$ & $6,63^{* *}$ \\
Hidratação $(\mathrm{H})$ & $8,94^{* *}$ \\
$\mathrm{~S} x \mathrm{~T}$ H & $1,89^{\mathrm{NS}}$ \\
$\mathrm{CV}(\%)$ & 7,15 \\
\hline
\end{tabular}

${ }^{1}$ Médias seguidas pela mesma letra não diferem, pelo teste de Tukey, a 0,01 de probabilidade ** Significativo a $0,01,{ }^{\text {NS }}$ Não significativo índice de velocidade de germinação foram obtidos nas mesmas temperaturas $\left(25\right.$ e $\left.30^{\circ} \mathrm{C}\right)$ embora Oliveira et al. (1998) avaliando a qualidade fisiológica de sementes peletizadas de cenoura, tenham obtido maiores valores para germinação e índices de velocidade de emergência em temperaturas diferentes. Semelhante ao verificado para sementes peletizadas de tomate, os mesmos autores constataram que o substrato entre papel também foi responsável pelos menores valores de índice de velocidade de emergência, em sementes peletizadas de cenoura. Em sementes de alface, Coraspe et al. (1993) verificaram que a peletização não influenciou a velocidade de germinação de sementes de alface, enquanto Santos et al. (2000) verificaram influência negativa da peletização no índice de velocidade de germinação de sementes da mesma espécie, e Resende et al. (2001) em sementes de pimentão.

\section{CONCLUSÕES}

1. Os substratos entre areia e vermiculita umedecidos com água em temperatura constante de 25 ou $30^{\circ} \mathrm{C}$, foram mais eficientes na avaliação da germinação e do vigor em sementes peletizadas de tomate.

2. A temperatura alternada de $20-30{ }^{\circ} \mathrm{C}$ e os substratos entre e sobre papel, não se mostraram adequados para avaliar sementes peletizadas de tomate.

\section{AGRADECIMENTOS}

Os autores expressam seus agradecimentos à Professora Sheila Costa de Faria, pela correção do Abstract; ao Engenheiro Agrônomo Antônio Alves de Lima e aos Laboratoristas Pedro Francisco da Silva, Rui Barbosa da Silva e Severino Francisco dos Santos, que viabilizaram a execução deste trabalho.

\section{LITERATURA CITADA}

Albrecht, J.M.F.; Albuquerque, M.C.F.E.; Silva, M.V.F. Influência da temperatura e do tipo de substrato na germinação de sementes de cerejeira. Revista Brasileira de Sementes, Brasília, v.8, n.1, p.49-55, 1986.

Almeida, N.O.; Davide, A.C.; Guimarães, R.M.; Oliveira, J.A. Avaliação da germinação de sementes peletizadas de Guazuma ulmifolia Lam. Informativo ABRATES, Curitiba, v.11, n.2, p.276, 2001.

Andrade, A.C.S. de; Pereira, T.S. Efeito do substrato e da temperatura na germinação e no vigor de sementes de cedro, Cedrela odorata L. (Meliaceae). Revista Brasileira de Sementes, Brasília, v.16, n.1, p.34-40, 1994.

Bewley, J.D.; Black, M. Viability, dormancy and environmental control. In: Bewley, J.D.; Black, M. (ed) Physiology and biochemistry of seeds. New York: Springer - Verlag, 1985, v.2.328p.

Borges, E.E. de L.; Rena, A.B. Germinação de sementes. In: Aguiar, I. B. de; Piña-Rodrigues, F.M.C.; Figliolia, M.B. (coords.) Sementes florestais tropicais. Brasília: ABRATES, 1993. cap.3-6, p.83-135. 
Brasil. Ministério da Agricultura e Reforma Agrária. Regras para análise de sementes. Brasília: Coordenação de Laboratório Vegetal - CLAV. Departamento Nacional de Defesa Vegetal, 1992.365p.

Carvalho, N.M. de; Nakagawa, J. Sementes: ciência, tecnologia e produção. 4. ed. Jaboticabal: FUNEP, 2000. 588p.

Coraspe, H.M.; Idiarte, H.G.; Minami, K. Avaliação do efeito da peletização sobre o vigor de sementes de alface (Lactuca sativa L.). Scientia Agrícola, Piracicaba, v.50, n.3, p.349-354, 1993.

Davide, A.C.; Almeida, N.O.; Oliveira, J.A.; Guimarães, R.M. Avaliação da germinação de sementes peletizadas de Eucalyptus grandis. Informativo ABRATES, Curitiba, v.11, n.2,p.273, 2001.

Figliolia, M.B.; Oliveira, E. de C.; Piña-Rodrigues, F.C.M. Análise de sementes. In: Aguiar, I.B. de; Piña-Rodrigues, F.C.M; Figliolia, M.B. (coords.). Sementes florestais tropicais, Brasília: ABRATES, 1993.p.137-174.

Giomo, G.S.; Almeida, C.; Rocha, S.C.S.; Razera, L.F. Qualidade fisiológica de sementes de brócolos (Brassica oleraceae L.). Informativo ABRATES., Curitiba, v.11, n.2, p.296, 2001.

Macchia, M.; Benvenuti, A.; Nesti, E. Germination characteristics of pelleted seeds of several vegetable species. Sementi Elette, Pisa, v.29, n.5, p.15-21, 1983.

Maguire, J.D. Speed of germination aid in selection and evaluation for seedling emergence and vigor. Crop Science, Madison, v.2, n.2, p.176-177, 1962.

Marcos Filho, J. Germinação de sementes. In: Cícero, S.M.; Marcos Filho, J.; Silva, W.S. (eds). Atualização em produção de sementes. Campinas: Fundação Cargill, 1986. p.11-39.

Martins, C.C.; Semene, A.M.; Castro, M.M.; Nakagawa, J.; Cavariani, C. Testes de vigor na avaliação da qualidade de sementes peliculizadas de brócolos. Informativo ABRATES., Curitiba, v.11, n.2, p.187, 2001.

Mayer, A.M.; Poljakoff-Mayber, A. The germination of seeds. 4.ed. London: Pergamon Press, 1989. 270p.

Oliveira, A.P. de; Ramos, L.R.M.; Martins, C.C. Influência de substratos e temperaturas sobre a germinação e vigor de sementes peletizadas de cenoura (Daucus carota L.). Agropecuária Técnica, Areia, v.19, n.1-2, p.60-65, 1998.
Pereira, C.E.; Oliveira, J.A.; Silva, J.B.C.; Resende, M.L. Desempenho de sementes de tomate revestidas com diferentes materiais. Horticultura Brasileira, Brasília, v.19, n.2, p.286, 2001.

Peterson, J.R.; Cooper, P.G. Some considerations of water in the germination test. Seed Science and Technology, Wageningen, v.7, n.3, p.329-340, 1979.

Resende, M.L.; Pereira, C.E.; Oliveira, J.A.; Guimarães, R.M.; Vieira, A.R. Qualidade fisiológica de sementes de pimentão (Capsicum annuиm L.) revestidas com diferentes materiais e submetidas ao tratamento pré-germinativo ("priming"). Informativo ABRATES, Curitiba, v.11, n.2, p.301, 2001.

Roos, E.E.; Moore, F.D. Effect of seed coating on performance of lettuce seeds in greenhouse soil tests. Journal of the American Society for Horticultural Science, Alexandria, v.100, n.5, p.573-576, 1975.

Sachs, M.; Cantliffe, D.J.; Nell, T.A. Germination studies of clay-coated sweet pepper seeds. Journal of the American Society for Horticultural Science, Alexandria, v.106, n.3, p.385-389, 1981.

Sachs, M.; Cantliffe, D.J.; Nell, T.A. Germination behavior of sand-coated sweet pepper seed. Journal of the American Society for Horticultural Science, Alexandria, v.107, n.3, p.412-416, 1982.

Santos, P.E.C.; Silva, J.B.C.; Nascimento, W.M. Avaliação de materiais para peletização de sementes de alface. Horticultura Brasileira, Brasília, v.18, Suplemento, p.1036-1037, 2000.

Silva, J.B.C. da; Nakagawa, J. Métodos para avaliação de materiais de enchimento utilizados na peletização de sementes. Horticultura Brasileira, Brasília, v.16, n.1, p.44-49, 1998a.

Silva, J.B.C. da; Nakagawa, J. Metodologia para avaliação de materiais cimentantes para peletização de sementes. Horticultura Brasileira, Brasília, v.16, n.1, p.31-37, 1998 b.

Silveira, S.R. Peletização de sementes: vantagens e efeitos na qualidade fisiológica e na longevidade. Informativo ABRATES, Brasília, v.7, n.1-2, p.66, 1997.

Vieira, R.D.; Bittencourt, M.; Panobianco, M. Vigor: um componente da qualidade de sementes. Informativo ABRATES, Curitiba, v.11, n.2, p.199, 2001. 